\title{
1 Root membrane ubiquitinome under short-term osmotic stress
}

2 Nathalie Berger ${ }^{1}$, Vincent Demolombe ${ }^{1}$, Sonia Hem ${ }^{1}$, Valérie Rofidal ${ }^{1}$, Laura Steinmann ${ }^{1,2}$, Gabriel

3 Krouk $^{1}$, Amandine Crabos $^{1}$, Philippe Nacry ${ }^{1}$, Lionel Verdoucq ${ }^{1}$, Véronique Santoni ${ }^{*}$

4

5 1: BPMP, CNRS, INRAE, Institut Agro, Univ Montpellier, 34060 Montpellier, France

62 2: Center for Computational and Theoretical Biology, University of Würzburg, Würzburg, Germany

$7 \quad{ }^{*}$ Author for communication: veronique.santoni@inrae.fr

8

\section{$9 \quad$ Author contributions}

NB performed the plant culture, protein extraction, immunopurification and LC-MS/MS analyses; VD analyzed the quantitative proteomics data and performed statistical analysis; SH conducted the MaxQuant analysis; VR contributed to the LC-MS/MS analyses; LS collected the in silico interactomics data; GK supervised and analyzed the interactomics data; AC and PN gathered the root phenotyping data; LV characterized the role of K3 ubiquitination; and VS conceived the project, designed the experiments, analyzed the data, and wrote the article.

\section{Funding}

This work was supported by a research contract from INRAE ("Biologie et Amélioration des Plantes, BAP" department).

\section{Keywords}

aquaporin, mass spectrometry, osmotic stress, ubiquitination

\section{Abbreviations}

K-Ub: ubiquitinated lysine

LC-MS/MS: liquid chromatography-tandem mass spectrometry

$L p_{r}$ : root hydraulic conductivity

PIP: plasma membrane intrinsic protein

Ub: ubiquitin

Ubi-peptides: ubiquitinated peptides

\section{Short title}




\section{Abstract}

Osmotic stress can be detrimental to plants, whose survival relies heavily on proteomic plasticity. Protein ubiquitination is a central post-translational modification in osmotic mediated stress. Plants use the ubiquitin $(\mathrm{Ub})$ proteasome system to modulate protein content, and a role for $\mathrm{Ub}$ in mediating endocytosis and trafficking plant plasma membrane proteins has recently emerged. In this study, we used the K-E-GG antibody enrichment method integrated with high-resolution mass spectrometry to compile a list of 719 ubiquitinated lysine (K-Ub) residues from 450 Arabidopsis root membrane proteins ( $58 \%$ of which are transmembrane proteins), thereby adding to the database of ubiquitinated substrates in plants. Although no Ub motifs could be identified, the presence of acidic residues close to K-Ub was revealed. Our ubiquitinome analysis pointed to a broad role of ubiquitination in the internalization and sorting of cargo proteins. Moreover, the simultaneous proteome and ubiquitinome quantification showed that ubiquitination is mostly not involved in membrane protein degradation in response to short osmotic treatment, but putatively in protein internalization as described for the aquaporin PIP2;1. Our in silico analysis of ubiquitinated proteins shows that two E2 Ub ligases, UBC32 and UBC34, putatively target membrane proteins under osmotic stress. Finally, we revealed a positive role for UBC32 and UBC34 in primary root growth under osmotic stress.

\section{Introduction}

Plants are exposed to different types of abiotic stress conditions such as drought or salinity that result in diminished plant growth and crop productivity (Lobell et al., 2011). Most of these conditions impose osmotic stress on plants by reducing the water potential of the environment. The consequences of osmotic stress manifest as inhibited cell elongation, stomata closure, reduced photosynthetic activity, the translocation of assimilates, changes in various metabolic processes, and disturbances in water and ion uptake. The ability of plants to survive these abiotic stresses relies heavily on their proteomic plasticity. Protein stability, activity, localization, and interactions with partners have all been widely described as governed by ubiquitination (Mukhopadhyay and Riezman, 2007; Nelson and Millar, 2015). Ubiquitin (Ub) is a 76-amino acid polypeptide that is highly conserved in eukaryotes and is ubiquitously found in tissues. It is linked to either target proteins or itself through the sequential action of three enzyme classes: Ub-activating enzymes (E1s), Ub-conjugating enzymes (E2s), and Ub ligases (E3s) (Callis, 2014). The activities of these enzymes ultimately result in the covalent 
conjugation of a single moiety (mono-ubiquitination), multiple Ub molecules that are individually attached (multi-mono-ubiquitination), or in the form of a chain (poly-ubiquitination) attached to a specific substrate. Poly-Ub chains are formed by the further attachment of Ub moieties linked together by one of the seven lysine residues present in a Ub molecule (K6, K11, K27, K29, K33, K48, and K63), or by the $\mathrm{N}$-terminal methionine in the form of head-tail linear repeats (Pickart and Eddins, 2004). Poly-Ub chains exhibit different topologies and are associated with diverse biological functions (Walsh and Sadanandom, 2014). As an example, poly-ubiquitination involving residue K48 from ubiquitin (K48-Ub linkage) triggers the degradation of target proteins by the $26 \mathrm{~S}$ proteasome (Pickart and Eddins, 2004). Much less is known about the other poly-ubiquitination chain linkages (Pickart and Eddins, 2004; Walsh and Sadanandom, 2014). The K63-Ub linkage has been widely studied in yeast and mammals and more recently in plants, and includes roles in the endocytosis of plasma membrane proteins, DNA damage responses and, to a lesser extent, autophagy and signaling (Komander and Rape, 2012; Romero-Barrios et al., 2020).

A role for ubiquitination in abiotic stress tolerance has emerged from the study of transgenic plants overexpressing Ub genes that become more tolerant to multiple abiotic stresses (Guo et al., 2008; Kang et al., 2016), and from the expression analysis of E2s and E3s. The Arabidopsis genome contains over 1,400 genes encoding E3s, 37 canonical E2s, and seven E2 variant proteins (Stone, 2018). The number of E3s associated with abiotic stress has increased dramatically over the last decade (Stone, 2018). In particular, exposure to stress (such as osmotic stress) increases abscisic acid levels; moreover, the number of E3s associated with regulating abscisic acid production, signaling, and response continues to grow, now including at least 25 different E3s (Stone, 2018). In addition to E3s, it appears that E2s are not only utilized as Ub-transferring components, but also play an active role in regulating the ubiquitination pathway (Zhou et al., 2010; Cui et al., 2012; Chen et al., 2016). Furthermore, E2 enzymes can interact directly with their targets (Liu et al., 2012; Pan et al., 2020). Indeed, recent studies have suggested that E2s regulate the specificity of target ubiquitination (Turek et al., 2018; Romero-Barrios et al., 2020).

The low stoichiometry and short lifespans of ubiquitinated proteins present obstacles to the identification of ubiquitinated proteins. K- $\varepsilon$-GG (DiGly, the remnant from ubiquitinated proteins following trypsin digestion) antibody affinity enrichment provides an efficient method to gain proteome-wide insight into ubiquitination processes, by capturing and concentrating this remnant of ubiquitinated proteins treated with trypsin prior to MS/MS (Xie et al., 2015; Guo et al., 2017; Zhang et al., 2017; Wang et al., 2019; He et al., 2020; Grubb et al., 2021). In the present study, we used a high-affinity K-E-GG antibody enrichment technique combined with high-accuracy MS/MS analyses to generate quantitative ubiquitinome and proteome profiles of root membrane proteins from plants treated with a short-term osmotic treatment. Altogether, we provide an extensive inventory of K-Ub 
105 residues in a membrane protein fraction, highlight the presence of acidic residues in the vicinity of 106 the $\mathrm{K}-\mathrm{Ub}$ residue, reveal a role for ubiquitination outside of the membrane protein degradation

107 process in response to short-term osmotic treatment, and demonstrate that the E2 ubiquitin ligases

108 UBC32 and UBC34 are positive regulators of primary root growth during osmotic stress.

109

110

111 


\section{Results}

113 The ubiquitinome response to osmotic stress was investigated by treating plants with $200 \mathrm{mM}$ 114 mannitol for $1 \mathrm{~h}$, followed by a combined quantitative analysis of the proteome and ubiquitinome of 115 a microsomal fraction, according to the proteomic workflow described in Figure 1.

\section{Differentially accumulated proteins in response to mannitol treatment}

118 A total of 6,081 proteins were identified based on an identification with at least 2 peptides (Table 119 S1), of which 26\% were transmembrane proteins (Table S1). Using GO analysis of cell component 120 terms, we showed that a majority of GO terms were associated with membrane proteins, even when 121 the extrinsic proteome (i.e. proteins without any transmembrane domain) was exclusively considered 122 (Figure S1). These results show that the microsomal fraction is enriched in membrane proteins. 123 Treating plants with $200 \mathrm{mM}$ mannitol for $1 \mathrm{~h}$ resulted in differentially accumulated proteins (DAPs), 124 which were identified through a quantitative label-free approach. Among the 226 DAPs that were identified, 132 were up-accumulated (average increase: 1.51x), and 94 were down-accumulated (average decrease: $0.61 x$ ) (Table S2). In addition, 1 protein appeared upon mannitol treatment, while 10 proteins disappeared (Table S2). DAPs were classified according to the GO functional categories of "biological process", "molecular function", and "cellular component" (Figure S2). Interestingly, enriched functions mostly concerned ATPase activities (Figure S2), in agreement with observations showing the tight regulation of plasma membrane $\mathrm{H}^{+}$-ATPase in response to several biotic and abiotic stress responses (Falhof et al., 2016).

\section{Characterization of the root membrane ubiquitinome}

To identify ubiquitinated proteins in Arabidopsis roots, we combined immunoaffinity enrichment (using a high quality anti-K-E-GG antibody; PTM biolabs) and high-resolution mass spectrometry. Ubiquitinated peptides (Ubi-peptides) were considered as long as they had a score $>40$ and if they were identified in at least two independent samples. 719 Ubi-peptides harboring a total of $786 \mathrm{~K}-\mathrm{Ub}$ residues belonging to 450 proteins were identified, 264 of which contained at least one transmembrane domain (Table S3, Table S4). Our GO enrichment analysis showed that ubiquitinated proteins were enriched in transporters, in proteins involved in the regulation of intracellular $\mathrm{pH}$, and in cellular trafficking processes that were characterized by the GO terms "vesicle budding from

142 membrane", "clathrin-dependent endocytosis" and "membrane invagination" (Figure 2) and included

14315 proteins (Table S3). These observations suggest that membrane proteins, as well as the proteins that drive their trafficking are ubiquitinated. 


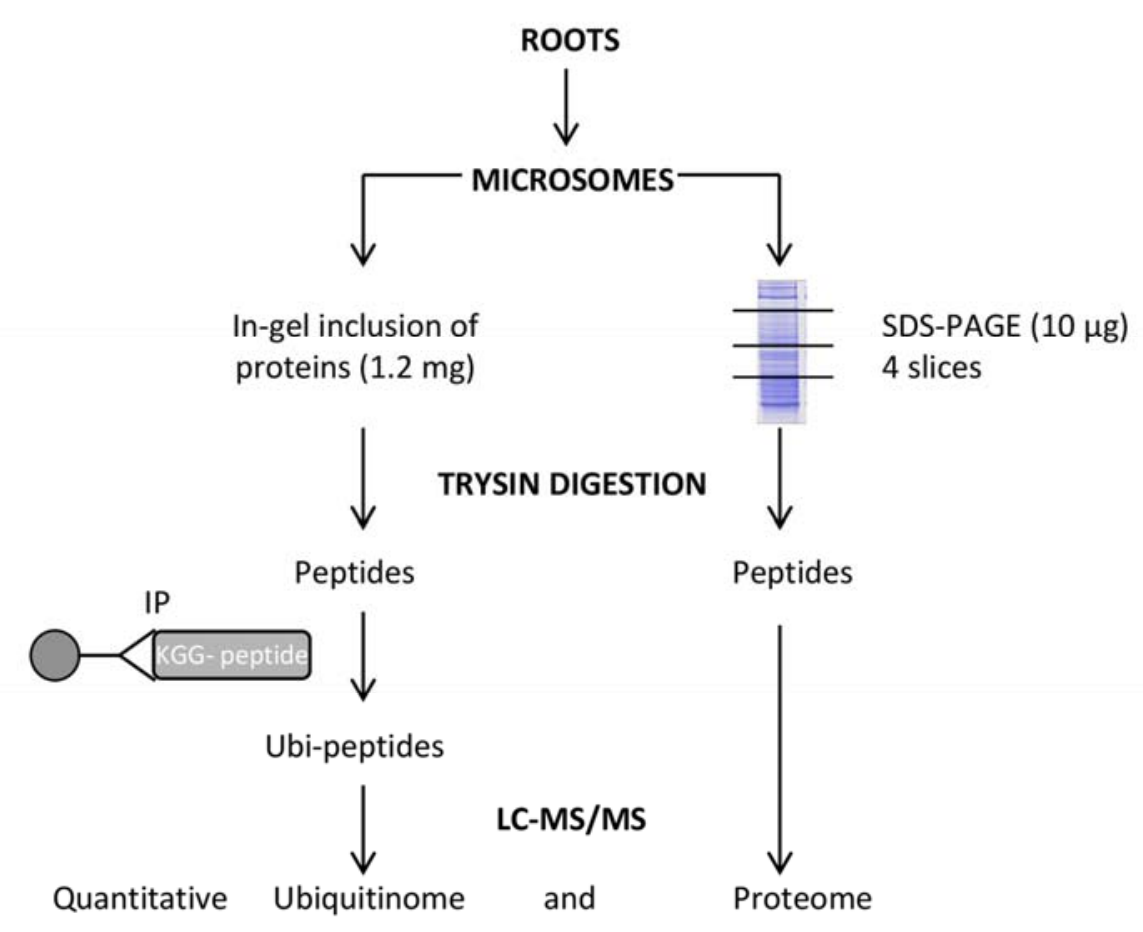

Figure 1. Workflow for quantitative profiling of the proteome and the ubiquitinome in Arabidopsis root membrane proteins upon mannitol treatment.

LC-MS/MS: liquid chromatography-tandem mass spectrometry.

IP: immunopurification.

145 Consensus peptide motifs for K-Ub residues were extracted using p-logo (O'Shea et al., 2013). In 146 total, 643 unique ubiquitinated sites were unable to highlight one unique motif (Table S5, Figure 3A-

147 B). However, the presence of an acidic amino acid close to K-Ub was observed in all motifs except 148 one. Although the nature of the poly-Ub linkage determines the role of ubiquitination, this 149 information is not available in a bottom-up proteomics strategy in which the use of trypsin induces 150 Ub proteolysis from ubiquitinated proteins. However, ubiquitinated peptides arising from the Ub 151 protein itself can provide information about poly-Ub linkages that occur in a protein sample. Seven K- 


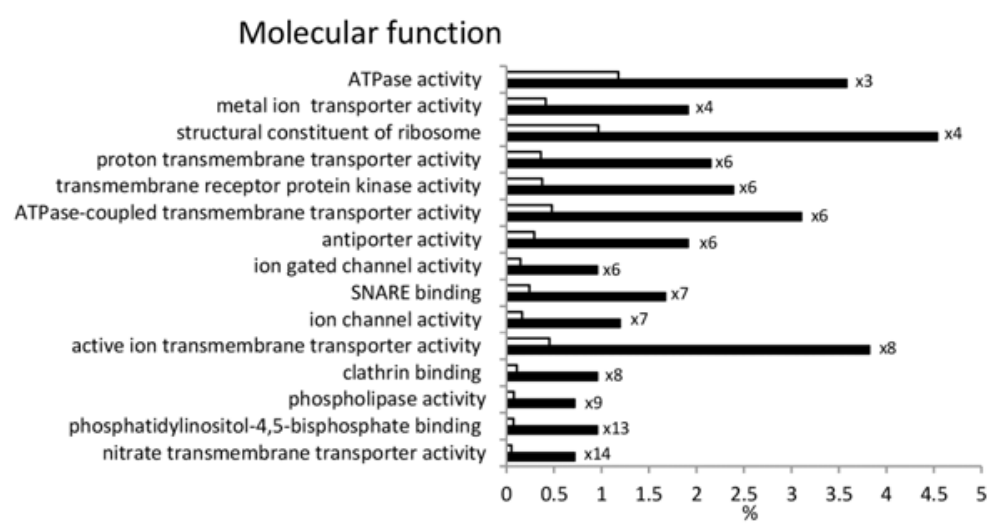

Biological process
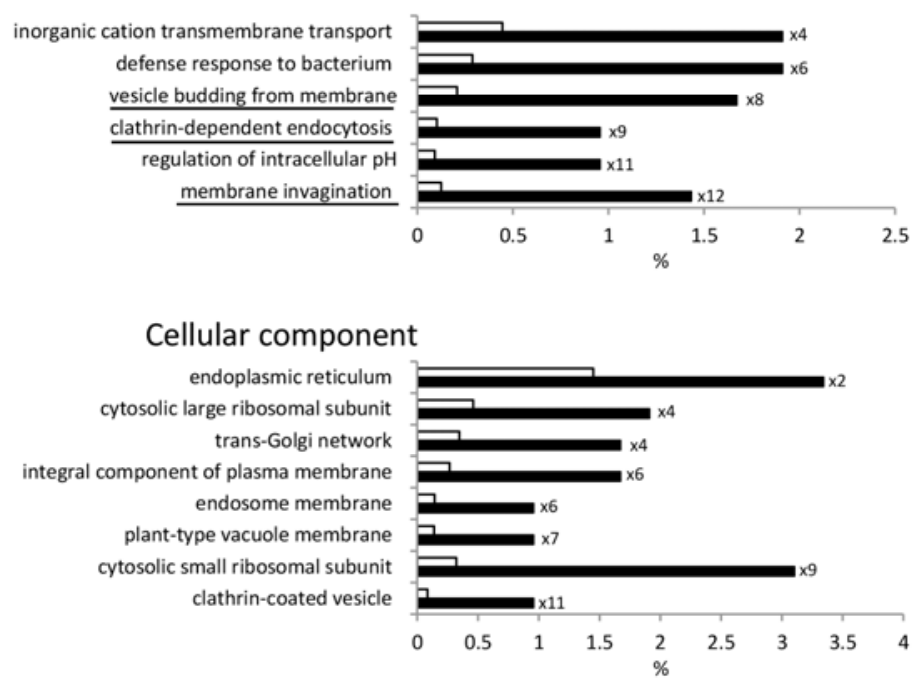

$\square$ Arabidopsis genome

Ubiquitinome

Figure 2. Functional enrichment analysis of ubiquitinated root microsomal proteins.

The percentage is calculated with regard to the number of identified ubiquitinated proteins (black) and the total number of Arabidopsis proteins (white). Numbers indicate the fold enrichment by comparison to the Arabidopsis genome. Underlined biological processes concern proteins involved in intracellular trafficking, and include 15 genes (Table S3).

152 Ubs were thus identified (K6, K11, K27, K29, K33, K48, K63) within Ub (Figure S3), showing multiple

153 Ub-linkages within membrane proteins. Although peptide intensity is not indicative of the absolute

154 quantity of each Ubi-peptide, the K48- and K63-Ub linkages appeared to predominate the poly-Ub

155 linkages (Figure S3). One way to confirm these observations would be with a targeted proteomics

156 approach that can provide absolute quantification of peptides (Tsuchiya et al., 2013). Nevertheless,

157 our results reveal that mannitol treatment does not significantly modify the proportion of each poly-

158 Ub linkage (Figure S3). 
A

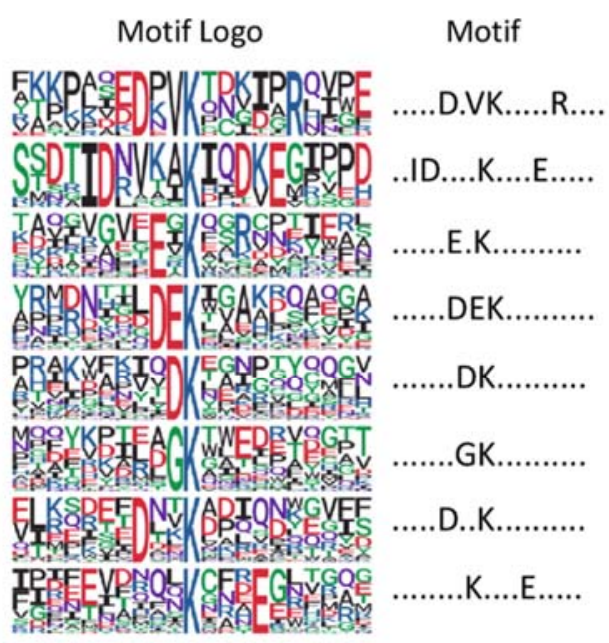

C

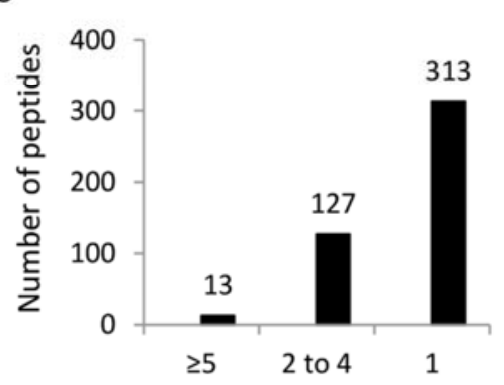

Ubiquitinated sites/protein

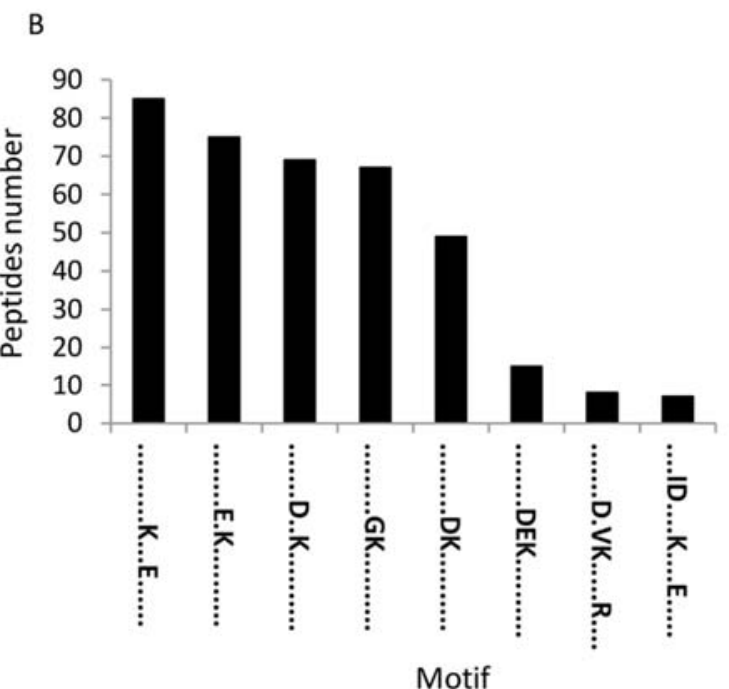

Motif

Figure 3. Motif analysis of identified $\mathrm{K}-\mathrm{Ub}$ residues in root microsomes.

A. Ubiquitination motifs and the conservation of K-Ub residues. The height of each letter corresponds to the frequency of the amino acid residue in that position. The central $\mathrm{K}$ refers to the $\mathrm{K}$-Ub residue. B. The number of identified peptides containing a $\mathrm{K}$-Ub residue in each motif. $\mathrm{C}$. The number of $\mathrm{K}$-Ub sites per protein.

159

\section{Differentially accumulated ubiquitinated proteins in response to mannitol treatment}

Out of 374 quantified Ubi-peptides, 82 showed quantitative variations in which 54 Ubi-peptides were up-accumulated and 28 were down-accumulated (Table S6). Enrichment-based clustering analyses showed that the ubiquitination of proteins altered by mannitol treatment mainly concerns ATPase, transporters and SNARE binding activities (Figure S4). An inverse quantitative relationship between a protein's abundance and its ubiquitinated form could be indicative of a role for ubiquitination in protein degradation. However, none of the 43 up-accumulated Ubi-peptides were affiliated with a decreased abundance in the corresponding protein (Table 1). In addition, among 24 downaccumulated Ubi-peptides, only 6 of them corresponded to accumulated proteins including CARK1, 
HIR2, NRT2;1, PIRL5, AT1G48210.2 and AT3G47210.1 (Table 1). Thus, a role for ubiquitination in degrading these protein could be considered. By contrast, for a majority of the proteins, the absence of any inverse quantitative relationship between the protein and its ubiquitinated form suggests that upon short-term osmotic treatment, ubiquitination could interfere with protein function or cellular localization rather than with protein stability.

\section{Ubiquitination of PIP aquaporins}

Aquaporins define a large family of ubiquitous integral membrane proteins that mediate the transport of water and small neutral solutes across membranes (Maurel et al., 2015). Plant aquaporins show a large variety of isoforms. Indeed, 35 homologs within four homology subclasses have been identified in Arabidopsis. The plasma membrane intrinsic proteins (PIPs) consist of 13 isoforms further subdivided into the PIP1 and PIP2 subgroups, and are the most abundant aquaporins in the plasma membrane (Johanson and Gustavsson, 2002; Quigley et al., 2002). All 13 members of the PIP family were identified in this study (Table S1), and 9 of them exhibited ubiquitinated residues in their $\mathrm{N}$ - and/or C-terminus (Table S3, Figure S5). Since only 3 lysine residues are described in the literature as ubiquitinated (Chen et al., 2021; Grubb et al., 2021), the present work greatly increases our knowledge regarding the ubiquitination of PIPs. Increased ubiquitination of K3 and K276 was observed in PIP2;1 upon short-term mannitol treatment (Table 1). K276 ubiquitination was recently shown to mediate PIP2;1 degradation upon long-term drought (Chen et al., 2021). However, since we observed that PIP2;1 cellular abundance was unchanged (Table 1), the increased ubiquitination of K276 observed when plants are subjected to a 1-h mannitol treatment cannot be involved in PIP2;1 degradation.

Next, we checked if there is a role for K3 ubiquitination using a simplified system of Arabidopsis suspension cells with a low basal level of endogenous PIPs. We overexpressed PIP2;1 either wild-type or carrying point mutations at K3 in alanine (K3A) and in arginine (K3R) (Santoni et al., 2006) with the aim of preventing ubiquitination at that site. We previously showed by western blot analysis of total protein extracts using an anti-PIP2;1 peptide antibody that there is a significantly strong overexpression of PIP2;1 in these cells, as compared to untransformed cells or cells transformed with an empty vector (PG) (Santoni et al., 2006). Here, using an ELISA assay, we observed a significant accumulation of PIP2;1 in suspension cells overexpressing PIP2;1-K3A and PIP2;1-K3R as compared to PIP2;1-WT (Figure 4), suggesting that K3 could be a ubiquitinable residue participating in the degradation of PIP2;1. However, in roots placed under short-term osmotic treatment, increased K3 ubiquitination did not correlate with decreased PIP2;1 abundance, suggesting (as for K276) an additional role for K3 ubiquitination outside of PIP2;1 degradation. 


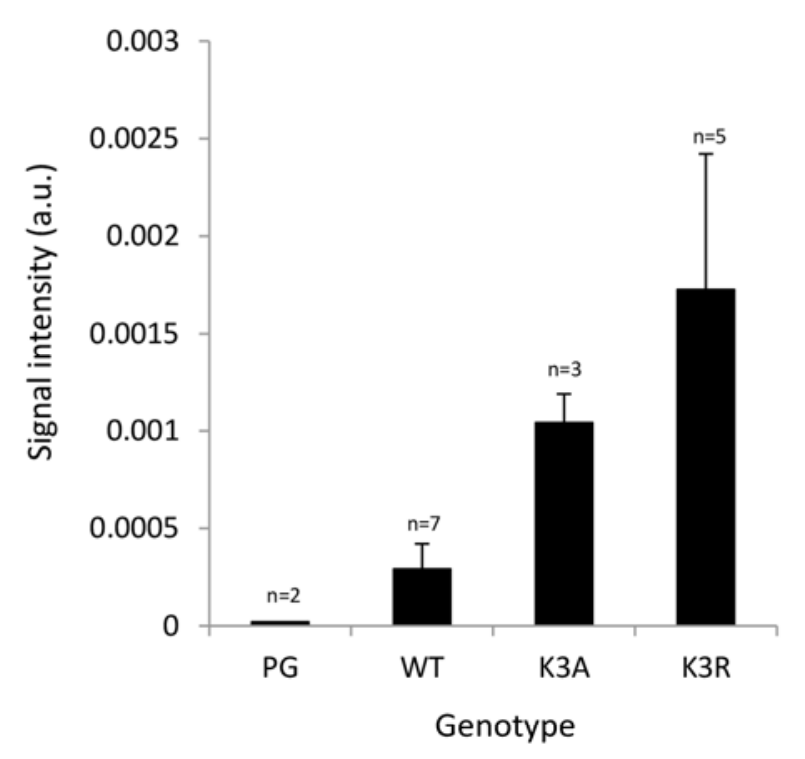

Figure 4. Relative abundance of PIP2 isoforms in Arabidopsis suspension cells overexpressing PIP2;1 WT and carrying a point mutation of $K 3$ in alanine (K3A) and in arginine (K3R).

ELISA assays were performed with total protein extracts and anti-PIP2 antibody (Santoni et al., 2006). The number of independent stable cell lines is indicated. Data were from three individual ELISA assays per cell line. Standard error is shown.

204

205

206

207

208

209

210

211

\section{The interactome of ubiquitinated proteins}

For additional insight into the extent of the role of ubiquitination, we next constructed a network for the ubiquitinated proteins identified in this work and their interactants identified in previous yeasttwo hybrid (Braun et al., 2011) and Split-Ub global approaches (Chen et al., 2012; Jones et al., 2014). This final network consisted of 1,011 proteins (Table S7a, Figure 5). Transport and trafficking functions were enriched in such interactome and, interestingly, the most enriched process concerns ubiquitination, with the GO term "protein K63 linked ubiquitination" showing a 37-fold enrichment (Figure S6). Five E2s (UBC26, UBC32, UBC34, UBC35, UEVD1) and one E3 (UPL6) were identified in this network (Table S7a). We investigated the extent of interaction of these enzymes with the ubiquitinated proteins identified in the present work, and identified two E2s, UBC32 and UBC34, which putatively interact with 15 and 31 ubiquitinated transmembrane proteins involved in water and ion transport, respectively (Figure 5; Table S7b-c). 
A

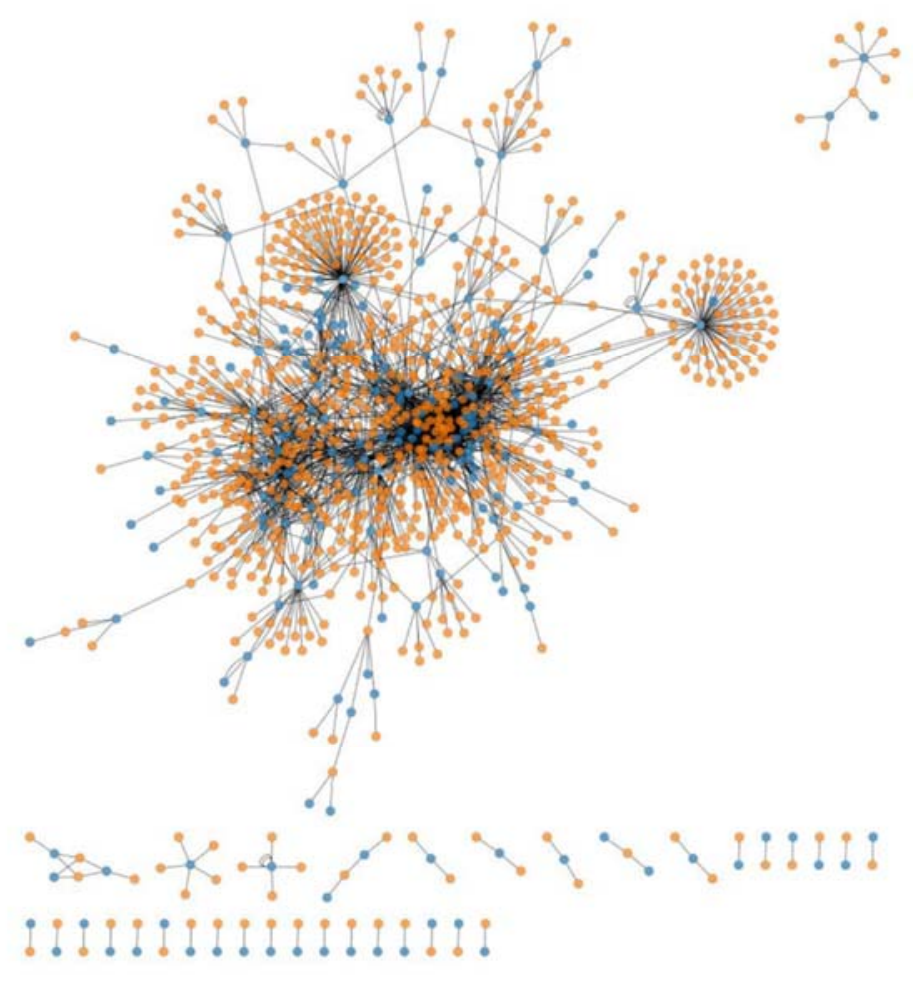

B

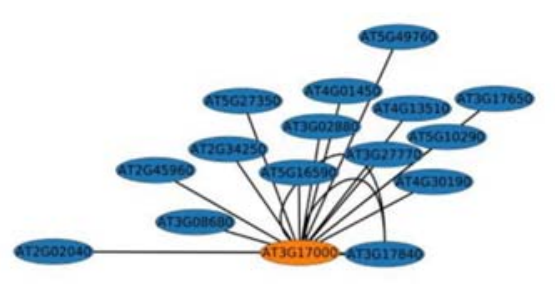

C

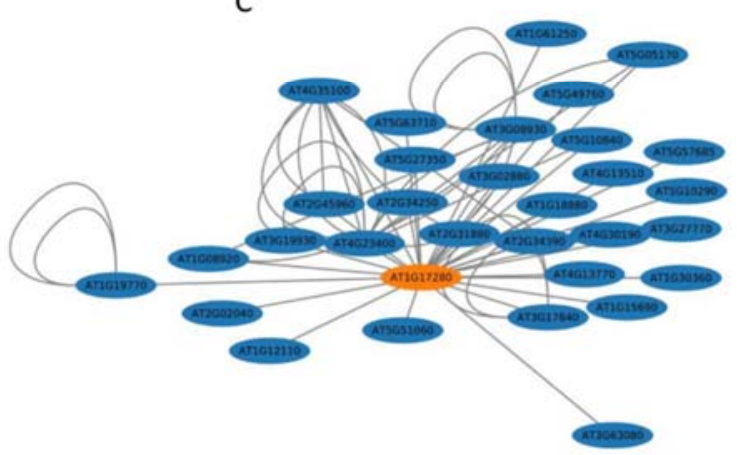

Figure 5. The interaction network of ubiquitinated proteins.

Interactants from a Y2H approach (Braun et al., 2011) and Split-Ub approach (Chen et al., 2012; Jones et al., 2014 ) were considered, and the network was visualized by Cytoscape (version 3.7.2). A. The network includes ubiquitinated proteins (blue) together with their reported interactants (orange) (Table S7a). B. The UBC32 subnetwork (see Table S7b). C. The UBC34 subnetwork (see Table S7c).

216 We then used a highly similar approach that focused specifically on DAUPs and their interactants,

217 which made it possible to build another network of 326 proteins enriched in transporters and

218 components of endocytic trafficking (Table S7d, Figure S7-S8). UBC32 and UBC34 appeared again as

219 E2s targeting 9 proteins whose ubiquitination changed with mannitol treatment (Figure S7, Table 1).

220 These proteins include NRT1;1-PTR8.3, NRT1-PTR6.3, two LRR-Receptor like kinases, a nodulin MtN21 
221 like transporter, AHA2, the secretory carrier-associated membrane protein SCAMP3, the peroxidase

222 GPX5, and an unknown protein.

223

224

225

226

227

228

229

230

231

232

233

234

235

236

237

238

239

240

241

242

243

244

245

\section{The osmotic phenotype of $u b c 32, u b c 33$ and $u b c 34$ mutants}

Root responses to osmotic stress involve high plasticity in root growth and architecture, which is partly determined by primary root (PR) growth. To reinforce the roles of UBC32 and UBC34 in the adaptive root response to osmotic stress, we studied the PR growth phenotype of corresponding mutants in control conditions and upon osmotic treatment. Since AtUBC32 and AtUBC34 belong to a small gene subfamily including UBC33 (Ahn et al., 2018), we also studied the ubc33 mutant and a triple knockout mutant line, $u b c 32 x u b c 33 \times u b c 34$, due to the putative redundancy between the 3 genes. Five-day-old plants were transferred to either control MS medium or MS medium supplemented with $0.2 \mathrm{M}$ mannitol, and PR length was monitored for up to 5 days after transfer (Figure 6, Figure S9, Table S8). The root growth in control WT plants (Col) was inhibited by $14 \%$ one day after transfer, and by up to $43 \%, 5$ days later (Figure 6). The $u b c 32$ and $u b c 34$ single mutants and the triple mutant showed a significantly higher PR growth inhibition ranging from $25 \%$ at day 1 after transfer up to $50 \%$ at day 5 after transfer (Figure 6). Thus, suppression of AtUBC32 and AtUBC34 favored PR growth inhibition under mannitol treatment, suggesting that these genes contribute to PR root growth under osmotic stress. This result is observable after only one day of treatment, suggesting that these genes play an early role in the response to osmotic stress. 


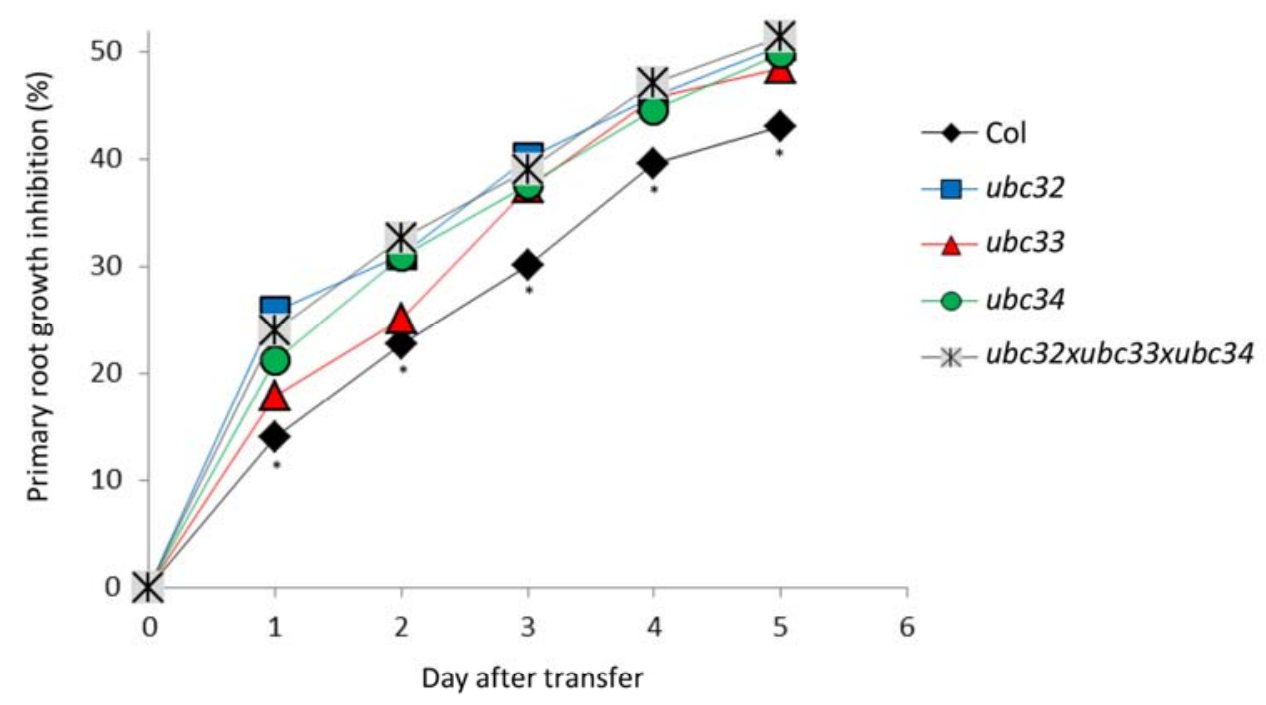

Figure 6. Inhibition of primary root length by mannitol in Arabidopsis thaliana WT plants (Col) and $u b c 32, u b c 33, u b c 34$ and $u b c 32 \times u b 33 \times u b c 34$ mutants.

15 plants per condition were grown for 5 days in MS medium and then transferred to MS medium and MS medium supplemented with $200 \mathrm{mM}$ mannitol. Primary root length was monitored up to 5 days after transfer (Figure S9). Asterisks means that the WT is significantly different from at least one mutant in a one-way ANOVA test combined with a Tukey test ( $p$-value between 0.01 and 0.001 (Table S8)).

\section{Discussion}

\section{A resource of ubiquitinated membrane proteins}

248 Our study included 450 ubiquitinated proteins, significantly increasing the database size of ubiquitinated membrane protein substrates in plants. In comparison to other large-scale Arabidopsis ubiquitinomes (Maor et al., 2007; Manzano et al., 2008; Kim et al., 2013; Svozil et al., 2014; Walton et al., 2016; Zhang et al., 2019; Romero-Barrios et al., 2020; Grubb et al., 2021), 207 novel proteins, $90 \%$ of which are transmembrane proteins, were identified as ubiquitinated (Table S9). We also observed that $20 \%$ of Ubi-peptides can be additionally modified by oxidation, phosphorylation and acetylation (Table 1, Table S4), adding complexity to cellular signaling. The major proton pump AHA2 harbors $21 \mathrm{~K}-\mathrm{Ub}$ sites (Tables S3), four of them showing quantitative variations upon mannitol treatment (Table 1). K888 in particular is ubiquitinated, and this site is located close to T881, whose

257 phosphorylation leads to pump activation (Fuglsang et al., 2014). Moreover, the doubly modified 258 peptide (i.e. by phosphorylation and ubiquitination) was accumulated upon mannitol treatment. 
259 Recent studies have highlighted the importance of crosstalk between phosphorylation and 260 ubiquitination in several plant signaling pathways (Vu et al., 2018), and the presence of such a K-Ub 261 near a critical phospho-residue questions the role of this ubiquitination in the modulation of ATPase 262 function.

263 Even though no ubiquitin motif could be described, the K-Ub residue appeared to be preferentially 264 surrounded by an acidic residue (Figure 3). Similar observations can be obtained from ubiquitinome 265 studies in petunia flower and rice embryo (Guo et al., 2017; He et al., 2020). By contrast, previous 266 studies in rice leaf, wheat seedling and maize leaf have reported that alanine is enriched around K-Ub 267 (Xie et al., 2015; Zhang et al., 2017; Wang et al., 2019). Thus, although no Ub motif could be 268 identified, the presence of an acidic residue appears to be a common feature between 3 different 269 tissues (root, flower, embryo), whereas the close presence of an alanine residue appears to be more 270 specific for ubiquitinated residues in leaf proteins.

271 Our ubiquitinome study revealed that one-third of ubiquitinated proteins (151 proteins) harbor more 272 than one ubiquitination site. In two recent studies, a total of 422 proteins were identified as carrying 273 a K63-Ub linkage (Johnson and Vert, 2016; Romero-Barrios et al., 2020). Seventy-four of these 274 proteins were identified in the present study, 29 of which were identified as carrying a unique K-Ub 275 site that can be preferentially accounted for a K63-Ub linkage (Table S10). However, 44 proteins were 276 also described in the present study as harboring at least $2 \mathrm{~K}$-Ub sites (Table S10). This suggests that either all K-Ub residues are involved in K63-Ub linkage, or that different types of Ub linkages coexist within the same protein, including K63-Ub. This type of coexistence has already been shown in several studies; notably, the traffic and degradation of a particular receptor tyrosine kinase is likely to be regulated by different K-48 and K-63 poly-Ub editing mechanisms (Marx et al., 2010). Furthermore, the human nuclear protein Twist regulates a variety of cellular functions controlled by gene transcription events and can be ubiquitinated through K48-Ub linkage, which induces proteasome-dependent proteolysis and K63-Ub linkage for localization to the nucleus (Lee et al., 2016). Finally, in plants, the ubiquitination pattern of oleosin includes K48-Ub linkage that induces the proteasomal protein degradation, as well K63-Ub linkage which role remains unknown 286 (Deruyffelaere et al., 2015). Thus, the specific fate of proteins can be dictated by specific coexisting 287 poly-Ub linkages.

288 In addition to transporters and channels, we reported that vesicle transport-related proteins 289 including clathrin assembly proteins, the AP-2 complex subunit, v-SNARE proteins, vesicle associated 290 proteins and syntaxins were overrepresented in the ubiquitinome (Table S3). Endocytosis and 291 endosomal trafficking are essential processes in cells for controlling the dynamics and turnover of 292 plasma membrane proteins (Valencia et al., 2016). The recruitment of cargo into endocytic vesicles 293 (e.g. clathrin-coated pits) involves the 'endosomal sorting complex required for transport' (ESCRT) 
multi-subunit complex, and requires adaptor proteins to eventually associate with clathrin (Valencia et al., 2016). The vesicles fuse with the acceptor organelle in a process mediated by factors such as SNAREs and small GTPases (Valencia et al., 2016). Here, we unexpectedly observed a concomitant ubiquitination of cargos and proteins from the endocytic machinery (Table S3). While a role for the ubiquitination of cargos in their endocytosis has recently emerged in plants (Romero-Barrios and Vert, 2018), the ubiquitination of proteins involved in endocytosis is rarely documented. In animals, several proteins involved in EGFR endocytosis were shown to be ubiquitinated after EGF stimulation (Haglund et al., 2002). In yeast, ubiquitination was recently shown to function as a recycling signal for sorting a SNARE into COPI vesicles in a non-degradative pathway (Xu et al., 2017). Therefore, our results suggest a role for ubiquitination in regulating the function of proteins involved in endocytic trafficking, highlighting a broad role for ubiquitin in internalizing and sorting cargo proteins.

\section{The role of ubiquitination in response to short-term osmotic treatment}

Because ubiquitination can induce protein degradation, we looked for an inverse relationship between the abundance of proteins and their ubiquitinated form that could indicate a role for ubiquitination in protein degradation. Caution must be taken with this assumption, since it is not until the ubiquitin chain is assembled that it may act as a degradation signal (Clague et al., 2015). If a large proportion of ubiquitin is likely to be attached as mono-ubiquitin, this might skew the inverse relationship between the abundance of a protein and its ubiquitinated form. Although we may have overestimated the number of concerned proteins, only $10 \%$ of them $(n=6)$ exhibited this inverse relationship, whereas $90 \%$ showed ubiquitination changes without any change in protein abundance (Table 1). Thus, for a majority of these membrane proteins, ubiquitination is not involved in protein degradation in response to short-term osmotic treatment. In particular, PIP2;1 abundance was unchanged upon short-term mannitol treatment, while its ubiquitination increased at K3 and K276 (Table 1). This osmotic treatment was shown to induce maximal $L p_{r}$ inhibition by $60 \%$, which can be accounted for by a decrease in aquaporin function (Di Pietro et al., 2013) and not PIP degradation, since the abundance of all PIPs was unchanged (Table S2). Thus, even though ubiquitination at K3 and K276 can be involved in PIP2;1 degradation (Figure 5, (Chen et al., 2021)), we assume that ubiquitination induces different consequences upon short-term mannitol treatment. Indeed, shortterm osmotic treatment induces PIP2;1 selective endocytosis (Martiniere et al., 2019). In addition, PIP2;1 is ubiquitinated by K63-Ub linkage (Johnson and Vert, 2016), a poly-Ub linkage that plays a general function in the sorting of endocytosed cargos by the endosomal sorting complex required for transport (Romero-Barrios and Vert, 2018). Thus, we hypothesize that the increase in PIP2;1 ubiquitination induced by short-term treatment should participate in internalizing PIP2;1 and not in 
term drought treatment, due to the simultaneous activity of UBC32 and the E3 ligase Rma1 in ubiquitinating PIP2;1 at K276 (Chen et al., 2021). The pairing of E3s with different E2s is dynamic and changes in response to external stimuli (Turek et al., 2018). Thus, under short-term osmotic stress, a specific E2/E3 combination that differs from UBC32/Rma1 could regulate PIP2;1 internalization. However, this hypothesis will require additional experiments.

\section{UBC32 and UBC34 contribute to primary root growth under osmotic stress}

336 E2s have recently emerged as key mediators of chain assembly, in particular by dictating the $\mathrm{K}$ residue within ubiquitin used to link the moieties in a chain (Turek et al., 2018). Our protein-protein network analysis identified UBC32 and UBC34 as E2s that putatively interact with proteins whose ubiquitination changed upon short mannitol treatment (Table 1, Figure S7). Recent expression studies have suggested that E2s participate in abiotic stress responses (Zhou et al., 2010; Zhiguo et al., 2015; Sharma and Bhatt, 2018). Surprisingly, the role of UBC32 appears contradictory, since it has been described as playing both negative and positive roles in response to long-term drought in (Ahn et al., 2018) and (Chen et al., 2021), respectively. In particular, the survival rate of 3-week-old ubc32 plants after 12-20 days of withholding water has been reported to be both higher and lower than WT plants in (Ahn et al., 2018) and (Chen et al., 2021), respectively. Our study reveals that, in the context of short-term osmotic treatment, UBC32 and UBC34 positively regulate PR growth, thus playing a positive role in osmotic stress tolerance. $U B C 32, U B C 33$ and $U B C 34$ are all reported to participate in the endoplasmic reticulum-associated degradation (ERAD) pathway in Arabidopsis, which is a major degradation system involved in removing misfolded or unfolded proteins retained in the ER (Cui et al., 2012; Chen et al., 2016; Chen et al., 2017; Zheng et al., 2019; Chen et al., 2021; Zhang et al., 2021). The involvement of ERAD components suggests that short-term osmotic stress may also result in ER/protein stress, which engages ERAD to control the secretion of plasma membrane proteins. However, upon 1-h mannitol treatment, proteins that putatively interact with UBC32 and UBC34 and show increased ubiquitination did not display any decreased cellular abundance (Table 1). We thus speculate that UBC32 and UBC34 are not simply ERAD components, but that they also participate in the ubiquitination process in other subcellular organelles such as the plasma membrane in response

357 to a short-term osmotic stress. In particular, an internalization of the aquaporin PIP2;1 (Chen et al., 358 2021) was observed upon a short-term osmotic stress (Martiniere et al., 2019). We thus speculate 359 that, upon a short-term osmotic stress, a rapid coordinated internalization of aquaporins and of ions 360 transporters involved in plant mineral nutrition could contribute to maintain a minimal root growth. 361 Conversely, absence of internalization would impair root development. Soil is extremely 362 heterogeneous and root growth maintenance under unfavorable local environment could allow the 
363 root tip to reach a more favorable environment and then to maintain on a longer term root foraging 364 and plant survival.

365

366

\section{Conclusion}

368 Our data present the ubiquitinome of root membrane proteins and its variation under osmotic 369 stress. Importantly, the results highlight specific post-translational modification patterns and suggest 370 approaches for exploring the physiological role of lysine ubiquitination in plants under osmotic stress.

371 Our results open new perspectives in the involvement of ubiquitination and trafficking of root plasma

372 membrane transporters in response to changes in local environment and future studies exploring the

373 function of these ubiquitination in PIP2;1 and ion transporters will be necessary to delineate its role

374 in the root nutrient foraging.

375 


\section{Material and methods}

\section{Plant materials and growth conditions}

378 Arabidopsis thaliana ecotype Columbia (Col-8) was used as the control wild type (WT) plant. The 379 atubc32 (SALK_092817), atubc33 (GABI_105_D10), atubc34 (SAIL_1249_C08) single T-DNA insertion 380 mutant alleles and the triple mutant atubc32xatubc33xatubc34 were obtained from (Ahn et al., 381 2018). Homozygosity of these mutants was verified using primers described in (Ahn et al., 2018). For proteome and ubiquitinome studies, WT seeds were surface-sterilized and sown in $0.2-\mathrm{mL}$ tubes containing $0.8 \%$ agar prepared in $\mathrm{pH} 5.5$ Hoagland-based solution $\left(0.5 \mathrm{mM} \mathrm{KH}_{2} \mathrm{PO}_{4}, 1.25 \mathrm{mM} \mathrm{KNO}_{3}\right.$, $0.75 \mathrm{mM} \mathrm{MgSO}_{4}, 1.5 \mathrm{mM} \mathrm{CaNO}_{3}, 50 \mu \mathrm{M} \mathrm{H}_{3} \mathrm{BO}_{3}, 0.7 \mu \mathrm{M} \mathrm{CuSO}_{4}, 1 \mu \mathrm{M} \mathrm{ZnSO}_{4}, 12 \mu \mathrm{M} \mathrm{MnSO}_{4}, 0.24 \mu \mathrm{M}$ $\mathrm{Na}_{2} \mathrm{MoO}_{4}, 50 \mu \mathrm{M} \mathrm{Fe}{ }^{3+}$-EDTA). After 7 days in the growth chamber, the bottoms of the tubes were cut off prior to transfer in 2.5-L opaque recipients in the same medium. Plants were grown for 8 weeks under short-day conditions ( $8 \mathrm{~h} / 16 \mathrm{~h}$ day $/ \mathrm{night} ; 23^{\circ} \mathrm{C} / 20^{\circ} \mathrm{C}$ day/night) at a light intensity of 160 $\mu \mathrm{mol} . \mathrm{m}^{-2} \cdot \mathrm{s}^{-1}$ and $65 \%$ humidity. Plants were treated with $0.2 \mathrm{M}$ mannitol for $1 \mathrm{~h}$. Roots were harvested and stored at $-80^{\circ} \mathrm{C}$ until analysis.

390

\section{Microsome extraction}

Roots were crushed with a PULVERISETTE 2 Mortar Grinder (Fritsch) in liquid nitrogen and microsomal proteins were extracted according to (Di Pietro et al., 2013), except that the grinding buffer contained $10 \mathrm{mM} \mathrm{N}$-ethylmaleimide and that the pellets were resuspended with a potter in $200 \mu \mathrm{L}$ of Laemmli $1 X$ buffer (65 mM Tris-HCl, pH 7.5, 5\% glycerol, 2\% SDS) (Laemmli, 1970). Proteins were quantified using a detergent compatible with the Bradford assay kit (Thermo Scientific).

\section{Protein digestion}

399 For proteome analysis, three independent biological replicates from the control condition and 400 mannitol-treated plants were used. $10 \mu \mathrm{g}$ of microsomes were fractionated using $10 \%$ precast SDS401 PAGE gel electrophoresis (Bio-Rad). After staining with Coomassie blue (R250, Bio-Rad), the gel was rinsed with acetic acid/methanol (Destain, Bio-Rad). Each lane was cut into 4 bands. For the ubiquitinome study, 2 independent biological replicates from the control condition and mannitoltreated plants were used, and microsomal fractions $(1.2 \mathrm{mg})$ were subjected to an in-tube acrylamide inclusion (13\% acrylamide/bis-acrylamide, 0.6\% ammonium persulfate, 2.5\% TEMED) adapted from

406 (Balliau et al., 2018). For proteome and ubiquitinome analyses, gel slices were treated according to (Chen et al., 2019), with the exception that proteins were alkylated with $50 \mathrm{mM}$ chloroacetamide for ubiquitinome experiments. Proteins were digested with trypsin (Sequencing Grade Modified Trypsin, 


\section{Enrichment of ubiquitinated peptides}

413 Tryptic peptides were filtered through a C18 cartridge (Sep-Pack Classic, Waters) equilibrated with $4140.1 \%$ TFA. After loading on the column, the peptides were washed twice with $0.1 \%$ TFA and then with $4150.1 \%$ TFA and 5\% ACN. Peptides were eluted with $0.1 \%$ TFA and $40 \%$ ACN, pooled, frozen overnight 416 at $-80^{\circ} \mathrm{C}$, and finally evaporated. Immunoprecipitation experiments were performed with $15 \mu \mathrm{L}$ of 417 Pan anti-glycine lysine antibody conjugated to agarose beads (PTM Biolabs, Chicago, IL, USA) 418 according to the manufacturer's instructions. Briefly, tryptic peptides were dissolved in $300 \mu \mathrm{L}$ of 419 WASH I (100 mM NaCl, 1 mM EDTA, 20 mM Tris-HCl, 0.25\% n-Dodecyl $\beta$-D-maltoside, pH 8.0), incubated $4 \mathrm{~h}$ at room temperature on a rotary shaker, and then sequentially washed 3 times with WASH I, 3 times with WASH II (100 mM NaCl, 1 mM EDTA, 20 mM Tris-HCl, pH 8.0), and 3 times with HPLC-grade water. The elution was performed 3 times with $100 \mu \mathrm{L}$ of $0.1 \%$ TFA. For the LC-MS/MS experiment, $300 \mu \mathrm{L}$ of pooled eluates were dried under vacuum centrifuge and resuspended in $2 \%$ FA.

\section{LC-MS/MS analysis}

427

The LC-MS/MS experiments were performed using a NCS 3500RS-ProFlow nano system (Thermo Fisher Scientific Inc., Waltham, MA, USA) interfaced online with a nano easy ion source and a QExactive Plus Orbitrap mass spectrometer (Thermo Fisher Scientific Inc, Waltham, MA, USA). The samples were analyzed in a data-dependent acquisition mode. For total proteome and ubiquitinome experiments, $2 \mu \mathrm{L}$ and $6 \mu \mathrm{L}$ of peptides were injected, respectively. Peptides were first loaded onto a pre-column (Thermo Scientific PepMap 100 C18, $5 \mu \mathrm{m}$ particle size, $100 \AA ̊$ pore size, $300 \mu \mathrm{m}$ i.d. x 5 $\mathrm{mm}$ length) from the Ultimate 3000 autosampler with $0.05 \%$ TFA in water at a flow rate of 10 $\mu \mathrm{L} / \mathrm{min}$. The peptides were separated by reverse-phase column (Thermo Scientific PepMap C18, $3 \mu \mathrm{m}$ particle size, $100 \AA ̊$ pore size, $75 \mu \mathrm{m}$ i.d. x $50 \mathrm{~cm}$ length) at a flow rate of $300 \mathrm{~nL} / \mathrm{min}$. After a 3-min loading period, the column valve was switched to allow elution of peptides from the pre-column onto the analytical column. The loading buffer (solvent A) consisted of $0.1 \%$ FA in water, and the elution buffer (solvent B) was $0.1 \%$ FA in $80 \%$ ACN. The employed 3-step gradient consisted of $4-25 \%$ of solvent B until 50 min for ubiquitinome (103 min for total proteome), then $25-40 \%$ of solvent B from 50 to $60 \mathrm{~min}$ for ubiquitinome (from 103 to $123 \mathrm{~min}$ for total proteome), and finally $40-90 \%$ of solvent B from 60 to $62 \mathrm{~min}$ (123 to $125 \mathrm{~min}$ for total proteome). The total run time was $90 \mathrm{~min}$ for

443 step. Peptides were transferred to the gaseous phase with positive ion electrospray ionization at 1.8 $444 \mathrm{kV}$. In the data-dependent acquisition procedure, the top 10 precursors were acquired between 375 445 and 1,500 m/z with a 2 Th (Thomson) selection window, a dynamic exclusion of $40 \mathrm{~s}$, a normalized 
collision energy of 27 , and resolutions of 70,000 for MS and 17,500 for MS2. Spectra were recorded

447 with Xcalibur software (4.3.31.9) (Thermo Fisher Scientific). The mass spectrometry proteomics data

448 were deposited at the ProteomeXchange Consortium via the PRIDE partner repository with the

449 dataset identifier PXD022249. The reviewer account details are: Username:

450 reviewer_pxd022249@ebi.ac.uk, Password: B1h58X9Q.

\section{Identification and quantification of whole proteome and ubiquitinome}

For the proteome and the ubiquitinome, the resulting MS/MS data were processed using MaxQuant with an integrated Andromeda search engine (version 1.6.6.0). Tandem mass spectra were searched against the TAIR10 database $(35,417$ entries). The minimal peptide length was set to 6 . The criteria "Trypsin/P" was chosen as the digestion enzyme. Carbamidomethylation of cysteine was selected as fixed modification and methionine oxidation, N-terminal acetylation and phosphorylation (S/T/Y) were systematically selected as variable modifications. Up to 4 missed cleavages were systematically allowed.

For proteome analysis, the mass tolerance of the precursor was 20 and $4.5 \mathrm{ppm}$ for the first and main searches, respectively, and was 20 ppm for the fragment ions. The function "match between run" was used. Proteins were identified provided that they contained one unique trypsin peptide. The rates of false peptide sequence assignment and false protein identification were fixed to be lower than 1\%. Quantification was performed with at least 2 peptides per protein, one of them unique to the protein. To investigate differentially expressed proteins, Student's t-test was performed using protein Label-Free Quantification (LFQ) intensity values when present in at least 2 replicates and in at least 2 biological replicates per condition. For ubiquitinome analysis, "GlyGly" on K residue was additionally specified as a variable modification. The function "match between run" was not applied. The minimum score for peptides was set to 40 . The intensity of each peptide from the "evidence" table was normalized to the sum of all peptide intensities in each sample, and a t-test was performed to investigate differentially-expressed peptides. The ubiquitinated peptides with consistent fold changes in two replicates were counted, and the significance of the abundance change among samples was evaluated as differentially expressed by a Student's t-test. A p-value < 0.05 was considered statistically significant. The appearance/disappearance of peptides was considered on condition of their presence in two biological replicates and the corresponding absence from the two other biological replicates. We

477 defined "absence" as no razor or unique peptide in any biological condition replicate, and 478 "presence" as the identification of at least one unique peptide in all replicates of a biological 479 condition. 
482 Gene Ontology (GO) term association and enrichment analyses were performed using Panther 483 (http://www.pantherdb.org/) (Mi et al., 2013). Fold enrichments were calculated based on the 484 frequency of proteins annotated to the term compared with their frequency in the Arabidopsis 485 proteome. The p-value combined with the false discovery rate (FDR) correction was used as criteria 486 of significant enrichment for GO catalogs, whereas a p-value $<0.05$ was considered to be enriched 487 for GO terms. The most specific subclasses were considered. The GO annotation was classified based on the "biological processes", "molecular functions" and "cellular components" categories. GO terms were reduced with rrvgo (https://ssayols.github.io/rrvgo/). The number of transmembrane domains was estimated with Aramemnon (http://aramemnon.botanik.uni-koeln.de/). The p-logo software (O'Shea et al., 2013) (https://plogo.uconn.edu/) was used to analyze the models of the sequences with amino acids in specific positions of ubiquitin-21-mers (10 amino acids upstream and downstream of the K-Ub site) in all of the protein sequences. In addition, the Arabidopsis proteome was used as the background database, and the other parameters were set to default values. Proteinprotein interaction data were obtained from plant interactome databases, including results from a yeast two-hybrid approach (Braun et al., 2011) and from Split-ubiquitin approaches (Chen et al., 2012; Jones et al., 2014), in order to build a network including these ubiquitinated proteins together with their reported interactants. Protein-protein interaction networks were visualized using Cytoscape version 3.7.2 (Shannon et al., 2003).

500

\section{Ectopic expression of PIP2;1 in suspension cells}

502 Mutated PIP2;1 cDNAs were constructed according to (Santoni et al., 2006). Biolistic transformation

503 of 5-day-old suspension cells was performed as described in (Santoni et al., 2006), and transformed 504 cells were selected on $50 \mathrm{mg} / \mathrm{L}$ of hygromycin. Briefly, independent transformed cells were isolated 505 and further cultured on $40 \mathrm{mg} / \mathrm{L}$ of hygromycin. Stable insertion of the T-DNA was checked by PCR, 506 and the expression of PIP was detected by western blot as described in (Santoni et al., 2006).

507 Extraction of total proteins from suspension cells and ELISA measurements of PIP2 abundance were 508 performed as described in (Santoni et al., 2006).

Root architecture analyses

511 Plants were stratified for 2 days at $4^{\circ} \mathrm{C}$ and grown vertically on agar plates containing half-strength 512 Murashige and Skoog (MS) medium supplemented with $1 \%(\mathrm{w} / \mathrm{v})$ sucrose and $2.5 \mathrm{mM}$ MES-KOH pH 5136 , in a self-contained imaging unit equipped with a $16 \mathrm{M}$ pixel linear camera, a telecentric objective 514 and collimated LED backlight. Plants were grown in the imaging automat dedicated growth chamber 
bioRxiv preprint doi: https://doi.org/10.1101/2021.12.06.471398; this version posted December 9, 2021. The copyright holder for this preprint (which was not certified by peer review) is the author/funder. All rights reserved. No reuse allowed without permission.

515 at $23^{\circ} \mathrm{C}$ in a $16-\mathrm{h}$ light/8-h dark cycle with $70 \%$ relative humidity and a light intensity of $185 \mu \mathrm{mol} . \mathrm{m}$

$516 \quad{ }^{2} \cdot s^{-1}$ (Vegeled Floodlight, Colasse Seraing, Belgium). Plates were imaged every day for 5 days.

517

518 
bioRxiv preprint doi: https://doi.org/10.1101/2021.12.06.471398; this version posted December 9, 2021. The copyright holder for this preprint (which was not certified by peer review) is the author/funder. All rights reserved. No reuse allowed without permission.

519 Table 1. Variations in the ubiquitinated peptide and the corresponding protein in response to

520 mannitol treatment

\begin{tabular}{|c|c|c|c|c|c|c|c|}
\hline AGI & Description & Ubi-peptide sequence & K-Ub & $\begin{array}{l}\text { Ubi- } \\
\text { peptide } \\
\text { ratio }\end{array}$ & Protein ratio & $\begin{array}{c}\text { UBC } \\
32\end{array}$ & $\begin{array}{l}\text { UBC } \\
34\end{array}$ \\
\hline \multicolumn{8}{|c|}{ proteins with decreased ubiquitination } \\
\hline AT1G01580.1 & FRO2 & IEAFITRDNDAGDEAKAGK & 528 & DISP & INV & & \\
\hline AT1G08090.1 & NRT2;1 & ATLEKAGEVAKDKFGK & 259 & DISP & $1.92(p=0.03)$ & & \\
\hline AT1G13480.1 & $\begin{array}{l}\text { Protein of unknown } \\
\text { function }\end{array}$ & LDSELTSLGKSIEIGK & 211 & DISP & INV & & \\
\hline AT1G32450.1 & NRT1;5 & $\mathrm{S}_{\mathrm{ac}} \mathrm{CLEIYNK} \underline{K} \mathrm{DTM} \mathrm{O}_{\mathrm{ox}} \underline{\mathrm{KK}}$ & 9 or 13 or 14 & DISP & INV & & \\
\hline AT1G48210.2 & $\begin{array}{l}\text { Protein kinase } \\
\text { superfamily protein }\end{array}$ & 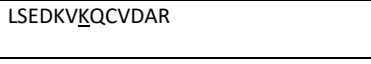 & 300 & DISP & $1.22(p=0.03)$ & & \\
\hline AT1G58030.1 & CAT2 & DGLLPSIFSDINKR & 369 & DISP & INV & & \\
\hline AT2G17440.1 & $\begin{array}{l}\text { PIRL5, ras group- } \\
\text { related }\end{array}$ & DITEKKGAQAVVQYMNDLVEAR & 484 & DISP & $1.51(p=0.01)$ & & \\
\hline AT2G23200.1 & $\begin{array}{l}\text { receptor-like protein } \\
\text { kinase }\end{array}$ & SKKGTIDEILDPSLIGQIETNSLKK & 710 & DISP & INV & & \\
\hline AT2G31610.1 & $\begin{array}{l}40 \mathrm{~S} \text { ribosomal } \\
\text { protein S3-1 }\end{array}$ & TQNVLGEKGRR & 62 & $\begin{array}{l}0.33(p= \\
0.01)\end{array}$ & INV & & \\
\hline AT3G01290.1 & HIR2 & AEGEAESKKYLSGLGIAR & 196 & DISP & $1.23(p=0.02)$ & & \\
\hline AT3G04840.1 & $\begin{array}{l}40 \mathrm{~S} \text { ribosomal } \\
\text { protein S3a-1 }\end{array}$ & NVGKKTLVSR & 45 & DISP & INV & & \\
\hline AT3G17410.1 & CARK1 & LSEDKVKGQVDAR & 301 & DISP & $1.27(p=0.03)$ & & \\
\hline AT3G47210.1 & $\begin{array}{l}\text { Protein of unknown } \\
\text { function }\end{array}$ & KYIISYINEQVELDSR & 62 & DISP & $1.28(p=0.03)$ & & \\
\hline AT3G51550.1 & Feronia & VLGVGGFGKVYYR & 549 & DISP & INV & & \\
\hline AT3G53480.1 & $\begin{array}{l}\text { ABC transporter } \\
\text { ABCG37, PDR9 }\end{array}$ & STLLDDGDESM ${ }_{\mathrm{ox}}$ TEKGGR & 88 & DISP & INV & & \\
\hline AT3G63080.1 & $\begin{array}{l}\text { glutathione } \\
\text { peroxidase }\end{array}$ & DSSGKEVVDLSVYQGK & 25 & DISP & INV & & yes \\
\hline AT4G08620.1 & SULTR1;1 & DFEKGQTPAK & 55 & DISP & INV & & \\
\hline AT4G33360.1 & $\begin{array}{l}\text { Farnesol } \\
\text { deshydrogenase }\end{array}$ & NVLEAVㅌETKKTVQK & $\begin{array}{l}112 \text { or } 115 \\
\text { or } 119\end{array}$ & DISP & INV & & \\
\hline AT4G37060.1 & $\begin{array}{l}\text { PATATIN-like protein } \\
5\end{array}$ & IDDDTLEGDASTLDLSTKKSNLENLIK & 340 & DISP & INV & & \\
\hline AT5G14040.1 & $\begin{array}{l}\text { Mitochondrial } \\
\text { phosphate carrier }\end{array}$ & FIKGSEGYGGLYK & 222 & DISP & INV & & \\
\hline AT5G56010.1 & HSP 90-3 & APFDLFDTKKK & 326 or 327 & DISP & INV & & \\
\hline AT5G65380.1 & $\begin{array}{l}\text { MATE efflux family } \\
\text { protein }\end{array}$ & VANELGAGNGKKGAR & 334 & DISP & INV & & \\
\hline \multicolumn{8}{|c|}{ proteins with increased ubiquitination } \\
\hline AT1G01580.1 & FRO2 & DNDAGDEAKAGKIIK & 528 and 531 & APP & INV & & \\
\hline AT1G02520.1 & $\begin{array}{l}\text { ABC transporter } \\
\mathrm{ABCB} 11, \mathrm{PGP} 11\end{array}$ & KQCEGPIKDGIK & 919 & APP & INV & & \\
\hline AT1G08930.2 & ERD6 & DTIDM $_{\mathrm{ox}}$ TENGGETKMSELFQR & 281 & APP & INV & & \\
\hline AT1G08930.2 & ERD6 & DTIDM $_{o x} T^{T E N G G E T K M} M_{o x} S E L F Q R$ & 281 & APP & INV & & \\
\hline AT1G11680.1 & $\begin{array}{l}\text { Sterol 14- } \\
\text { demethylase }\end{array}$ & SGKKTENDM ${ }_{\text {ox }}$ LQCFIESK & 253 & APP & INV & & \\
\hline AT1G12110.1 & NRT1, NPF6.3 & $\underline{\text { KLELPADPSYLYDVDDIIAAEGS }}{ }_{\mathrm{ph}} \mathrm{M}_{\mathrm{ox}} \underline{\mathrm{K}} \underline{\mathrm{K}} \underline{\mathrm{K}}$ & $\begin{array}{l}267 \text { or } 291 \\
\text { or } 293\end{array}$ & APP & INV & & yes \\
\hline AT1G44170.3 & ALDH3H1 & LSKLLLDEK & 242 & APP & INV & & \\
\hline AT1G55450.1 & methyltransferase & $\mathrm{A}_{\mathrm{ac}} \mathrm{ALSD} \underline{\mathrm{K}} \mathrm{LADAYQNAR}$ & 6 & $\begin{array}{l}2.3(p= \\
0.01)\end{array}$ & INV & & \\
\hline AT1G59870.1 & $\begin{array}{l}\text { ABC transporter } \\
\mathrm{ABCB} 11, \mathrm{PDR} 8\end{array}$ & EVDVTKLLDGEDRQK & 94 & APP & INV & & \\
\hline AT1G61250.2 & $\begin{array}{l}\text { Secretory carrier- } \\
\text { associated } \\
\text { membrane protein }\end{array}$ & ELQAKEEAELK & 71 & APP & INV & & yes \\
\hline AT1G61670.1 & $\begin{array}{l}\text { Two-component } \\
\text { response regulator }\end{array}$ & NELLFGLPDDVEEGKKRE & 511 & APP & INV & & \\
\hline AT2G02040.1 & NRT1, NPF 8.3 & AAVISEEESKKSGDYSNSWR & 325 & APP & INV & yes & yes \\
\hline AT2G24720.1 & $\begin{array}{l}\text { GLR2.2, glutamate } \\
\text { receptor } 2.2\end{array}$ & DLWKEEFLK & 864 & APP & INV & & \\
\hline AT2G32270.1 & Zinc transporter 3 & VSDGET $_{\mathrm{ph}}$ GESSVDSEKVQILR & 177 & APP & INV & & \\
\hline AT2G38360.1 & $\begin{array}{l}\text { PRA1.B4, prenylated } \\
\text { RAB acceptor 1.B4 }\end{array}$ & SALSKKPESISDAAVR & 68 & $\begin{array}{l}1.72(p= \\
0.02)\end{array}$ & INV & & \\
\hline AT2G47000.1 & $\begin{array}{l}\text { ABC transporter } \\
\text { ABCB4, PGP4 }\end{array}$ & $\mathrm{A}_{\mathrm{ac}} \mathrm{SESGLNGDPNILEEVSET} \underline{K} \mathrm{R}$ & 21 & APP & INV & & \\
\hline
\end{tabular}


bioRxiv preprint doi: https://doi.org/10.1101/2021.12.06.471398; this version posted December 9, 2021. The copyright holder for this preprint (which was not certified by peer review) is the author/funder. All rights reserved. No reuse allowed without permission.

\begin{tabular}{|c|c|c|c|c|c|c|c|}
\hline AT3G04840.1 & $\begin{array}{l}\text { 40S ribosomal } \\
\text { protein S3a-1 }\end{array}$ & IASEGLKKHR & 62 & APP & INV & & \\
\hline AT3G08680.2 & $\begin{array}{l}\text { Probable inactive } \\
\text { receptor kinase }\end{array}$ & AYYFSSKDEK & 407 or 410 & APP & INV & yes & \\
\hline AT3G27770.2 & $\begin{array}{l}\text { HUP53, HYPOXIA } \\
\text { RESPONSE PROTEIN } \\
53\end{array}$ & SPLIDGDNM $_{\mathrm{ox}}$ VSFEEKR & 125 & APP & INV & yes & yes \\
\hline AT3G29310.1 & BAG1 & FVQYVDDCVVKR & 230 & APP & INV & & \\
\hline AT3G45710.1 & NRT1, NPF2.5 & DEDYHQYGLGKEAK & 272 & APP & INV & & \\
\hline AT3G51550.1 & Feronia & AATKNFDESR & 534 & APP & INV & & \\
\hline AT3G53420.2 & PIP2;1 & ASGSKKSLGS ${ }_{\mathrm{ph}} \mathrm{FR}$ & 276 & $\begin{array}{l}1.79(p= \\
0.01)\end{array}$ & INV & yes* & \\
\hline AT3G53420.2 & PIP2;1 & $\mathrm{A}_{\mathrm{ac} \underline{\mathrm{K}} \mathrm{DVVAAVPGEGFOTR}}$ & 3 & $\begin{array}{l}1.69(p= \\
0.015)\end{array}$ & INV & yes* & \\
\hline AT3G60330.2 & AHA7 & TQHGLETGQKEPYYER & 903 & APP & $1.26(p=0.01)$ & & \\
\hline AT3G62250.1 & $\begin{array}{l}40 S \text { ribosomal } \\
\text { protein S27a-3 }\end{array}$ & MQIFVKTLTGKKIITLEVESSDTIDNVK & 11 & APP & INV & & \\
\hline AT4G01440.1 & $\begin{array}{l}\text { nodulin MtN21 } \\
\text { EamA-like }\end{array}$ & FNEDDQEEDDDEQYKKK & 354 or 355 & APP & INV & & \\
\hline AT4G09000.1 & GRF1 & AVDKKDELTVEER & 42 & APP & INV & & \\
\hline AT4G25090.1 & RBOHG & $\underline{K}^{\prime}$ LSDM $_{\text {ox }}$ LTESLKPTR & 267 & APP & INV & & \\
\hline AT4G30190.1 & AHA2 & AWLNLFENK & 857 & APP & $1.44(p=0.01)$ & yes & yes \\
\hline AT4G30190.1 & AHA2 & WSEQEAAILVPGDIVSII & 157 & APP & $1.44(p=0.01)$ & yes & yes \\
\hline AT4G30190.1 & AHA2 & $\mathrm{T}_{\mathrm{ph}}$ LHGLQPKEEAVNIFPEK & 888 & APP & $1.44(p=0.01)$ & yes & yes \\
\hline AT4G30190.1 & AHA2 & $\mathrm{S}_{\mathrm{ac}}$ SLEDIKNETVDLEK & 8 & $\begin{array}{l}3.00(p= \\
0.02)\end{array}$ & $1.44(p=0.01)$ & yes & yes \\
\hline AT5G25930.1 & $\begin{array}{l}\text { LRR protein kinase } \\
\text { family protein }\end{array}$ & LLVYEYLEEKR & 767 & APP & INV & & \\
\hline AT5G35200.1 & $\begin{array}{l}\text { putative clathrin } \\
\text { assembly protein }\end{array}$ & EAPLAAGVKKK & 310 & APP & INV & & \\
\hline AT5G39510.1 & v-SNARE 11 & KILTDM $_{\text {ox }}$ TR & 184 & APP & INV & & \\
\hline AT5G47910.1 & RBOHD & NKLLNLPNFLK & 541 & APP & INV & & \\
\hline AT5G59970.1 & $\begin{array}{l}\text { Histone superfamily } \\
\text { protein }\end{array}$ & DNIQGITKYPAIR & 32 & $\begin{array}{l}1.57(p= \\
0.02) \\
\end{array}$ & INV & & \\
\hline AT5G62300.2 & $\begin{array}{l}40 \mathrm{~S} \text { ribosomal } \\
\text { protein } \mathrm{S} 20-1\end{array}$ & 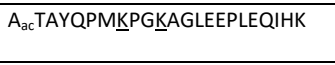 & 9 and 12 & APP & INV & & \\
\hline AT5G62390.1 & BAG7 & AIAAAEAEKK & 195 & APP & INV & & \\
\hline AT5G62390.1 & BAG7 & LEPEYPLKKYLCDR & 90 & $\begin{array}{l}3.02(p= \\
0.03)\end{array}$ & INV & & \\
\hline AT5G62390.1 & BAG7 & RLEPEYPLKKYLCDR & 90 & $\begin{array}{l}2.09(p= \\
0.01)\end{array}$ & INV & & \\
\hline
\end{tabular}

521 The table describes proteins for which protein and ubiquitin peptide quantification data are available

522 Columns 1 and 2: AGI and protein name.

523 Column 3: the ubiquitinated residue is underlined. ox: oxidation; ac: acetylation; ph:

524 phosphorylation.

525 Column 4: K-Ub position in the protein.

526 Column 5: the quantitative ratio of Ubi-peptide between mannitol and control experiments, with the

527 associated p-value. APP: appearance; DISP: disappearance.

528 Column 6: the protein quantitative ratio between mannitol and control experiments, with the

529 associated p-value. INV: invariant protein.

530 Columns 7 and 8: protein interaction with UBC32 and UBC34 (Braun et al., 2011; Chen et al., 2012,

531 Jones et al., 2014). *: Chen et al. 2021

532

533

534 


\section{Supplemental material}

536 Supplemental Figure S1. Characterization of the microsomal fraction.

537 Supplemental Figure S2. Functional enrichment analysis of differentially accumulated proteins (DAPs)

538 in response to mannitol.

539 Supplemental Figure S3. Types of Ub linkages.

540 Supplemental Figure S4. Functional enrichment analysis of differentially accumulated ubiquitinated

541 proteins (DAUPs) in response to mannitol.

542 Supplemental Figure S5: K-Ub residues in PIP aquaporins.

543 Supplemental Figure S6: Functional enrichment analysis of the interactome of ubiquitinated proteins

544 (corresponding to Figure 6).

545 Supplemental Figure S7: Interaction network of DAUPs.

546 Supplemental Figure S8: Functional enrichment analysis of the DAUP interactome.

547 Supplemental Figure S9: Root growth phenotype of WT plants and ubc mutants in 3-day control and

$548 \quad 0.2 \mathrm{M}$ mannitol conditions.

549

550 Supplemental Table S1: The root microsomal proteome of plants in the control condition and upon

551 mannitol treatment.

552 Supplemental Table S2: Proteins with quantitative variations upon mannitol treatment.

553 Supplemental Table S3: Inventory of ubiquitinated proteins in a root microsomal fraction.

554 Supplemental Table S4: Inventory of Ubi-peptides in root microsomes.

555 Supplemental Table S5: Determination of the ubiquitination motif.

556 Supplemental Table S6: Peptide quantification after immunopurification with the anti-KGG antibody.

557 Supplemental Table S7a: Interaction network of ubiquitinated proteins.

558 Supplemental Table S7b: Interaction network of UBC32.

559 Supplemental Table S7c: Interaction network of UBC34.

560 Supplemental Table S7d: Interaction network of DAUPs.

561 Supplemental Table S8a: One-way analysis of variance of root growth inhibition upon 1-day

562 treatment with $0.2 \mathrm{M}$ mannitol (corresponding to Figure 6).

563 Supplemental Table S8b: One-way analysis of variance of root growth inhibition upon 2-day

564 treatment with $0.2 \mathrm{M}$ mannitol (corresponding to Figure 6).

565 Supplemental Table S8c: One-way analysis of variance of root growth inhibition upon 3-day

566 treatment with $0.2 \mathrm{M}$ mannitol (corresponding to Figure 6).

567 Supplemental Table S8d: One-way analysis of variance of root growth inhibition upon 4-day

568 treatment with $0.2 \mathrm{M}$ mannitol (corresponding to Figure 6). 
569 Supplemental Table S8e: One-way analysis of variance of root growth inhibition upon 5-day

570 treatment with $0.2 \mathrm{M}$ mannitol (corresponding to Figure 6).

571 Supplemental Table S9a: Ubiquitinated proteins described in other Arabidopsis ubiquitome studies.

572 Table S9b: Novel ubiquitinated proteins identified in the present work.

573 Supplemental Table S10: Ubiquitinated proteins identified in the present work and described in the

574 literature as containing a K63-Ub linkage.

575

576

577

578 Acknowledgments

579 We thank Dr. Ahn (Yonsei University, Seoul, Republic of Korea) for providing seeds of mutant ubc32,

$580 u b c 33, u b c 34$ plants and the triple mutant $u b c 32 x u b c 33 x u b c 34$. We thank Brandon Loveall of

581 Improvence for English proofreading of the manuscript.

582

583

584 Conflict of interest statement. The authors declare no conflicts of interest.

585

586

\section{Data availability statement}

588 The mass spectrometry proteomics data were deposited at the ProteomeXchange Consortium via the

589 PRIDE partner repository with the dataset identifier PXD022249.

590

591 
bioRxiv preprint doi: https://doi.org/10.1101/2021.12.06.471398; this version posted December 9, 2021. The copyright holder for this preprint (which was not certified by peer review) is the author/funder. All rights reserved. No reuse allowed without permission. 


\section{Parsed Citations}

Ahn MY, Oh TR, Seo DH, Kim JH, Cho NH, Kim WT (2018) Arabidopsis group XIV ubiquitin-conjugating enzymes AtUBC32, AtUBC33, and AtUBC34 play negative roles in drought stress response. Journal of Plant Physiology 230: 73-79

Google Scholar: Author Only Title Only Author and Title

Balliau T, Blein-Nicolas M, Zvy M (2018) Evaluation of Optimized Tube-Gel Methods of Sample Preparation for Large-Scale Plant Proteomics. Proteomes 6

Google Scholar: Author Only Title Only Author and Title

Braun P, Carvunis AR, Charloteaux B, Dreze M, Ecker JR, Hill DE, Roth FP, Vidal M, Galli M, Balumuri P, Bautista V, Chesnut JD, Kim RC, de los Reyes C, Gilles P, Kim CJ, Matrubutham U, Mirchandani J, Olivares E, Patnaik S, Quan R, Ramaswamy G, Shinn P,

Swamilingiah GM, Wu S, Byrdsong D, Dricot A, Duarte M, Gebreab F, Gutierrez BJ, MacWilliams A, Monachello D, Mukhtar MS, Poulin MM, Reichert P, Romero V, Tam S, Waaijers S, Weiner EM, Cusick ME, Tasan M, Yazaki J, Ahn YY, Barabasi AL, Chen HM, Dangl JL,

Fan CY, Gai LT, Ghoshal G, Hao T, Lurin C, Milenkovic T, Moore J, Pevzner SJ, Przulj N, Rabello S, Rietman EA, Rolland T, Santhanam B, Schmitz RJ, Spooner W, Stein J, Vandenhaute J, Ware D, Arabidopsis Interactome Mapping C (2011) Evidence for network evolution in an Arabidopsis Interactome map. Science 333: 601-607

Google Scholar: Author Only Title Only Author and Title

Callis J (2014) The Ubiquitination Machinery of the Ubiquitin System Arabidopsis book 12

Chen J, Lalonde S, Obrdlik P, Vatani AN, Parsa SA, Vilarino C, Revuelta JL, Frommer WB, Rhee SY (2012) Uncovering Arabidopsis membrane protein interactome enriched in transporters using mating-based split ubiquitin assays and classification models. Frontiers Plant Sci. doi: 10.3389/fpls.2012.00124

Google Scholar: Author Only Title Only Author and Title

Chen Q, Liu R, Wu Y, Wei S, Wang Q, Zheng Y, Ran X, Shang X, Yu F, Yang X, Liu L, Huang X, Wang Y, Xie Q (2021) ERAD-related E2 and E3 enzymes modulate the drought response by regulating the stability of PIP2 aquaporins. The Plant Cell 33: 2883-2898

Google Scholar: Author Only Title Only Author and Title

Chen Q, Liu RJ, Wang Q, Xie Q (2017) ERAD Tuning of the HRD1 Complex Component AtOS9 Is Modulated by an ER-Bound E2, UBC32. Molecular Plant 10: 891-894

Google Scholar: Author Only Title Only Author and Title

Chen Q, Zhong YW, Wu YR, Liu LJ, Wang PF, Liu RJ, Cui F, Li QL, Yang XY, Fang SY, Xie Q (2016) HRD1-mediated ERAD tuning of ERbound E2 is conserved between plants and mammals. Nature Plants 2

Google Scholar: Author Only Title Only Author and Title

Chen Y, Rofidal V, Hem S, Gil J, Nosarzewska J, Berger N, Demolombe V, Bouzayen M, Azhar BJ, Shakeel SN, Schaller GE, Binders BM, Santoni V, Chervin C (2019) Targeted Proteomics Alows Quantification of Ethylene Receptors and Reveals SIETR3 Accumulation in Never-Ripe Tomatoes. Frontiers in Plant Science 10

Google Scholar: Author Only Title Only Author and Title

Clague MJ, Heride C, Urbe S (2015) The demographics of the ubiquitin system. Trends in Cell Biology 25: 417-426

Google Scholar: Author Only Title Only Author and Title

Cui F, Liu LJ, Li QL, Yang CW, Xie Q (2012) UBC32 Mediated Oxidative Tolerance in Arabidopsis. Journal of Genetics and Genomics 39: 415-417

Google Scholar: Author Only Title Only Author and Title

Deruyffelaere C, Bouchez I, Morin H, Guillot A, Miquel M, Froissard M, Chardot T, D'Andrea S (2015) Ubiquitin-Mediated Proteasomal Degradation of Oleosins is Involved in Oil Body Mobilization During Post-Germinative Seedling Growth in Arabidopsis. Plant and Cell Physiology 56: 1374-1387

Google Scholar: Author Only Title Only Author and Title

Di Pietro M, Vialaret J, Li G-W, Hem S, Prado K, Rossignol M, Maurel C, Santoni V (2013) Coordinated post-translational responses of aquaporins to abiotic and nutritional stimuli in Arabidopsis roots. Molecular and Cellular Proteomics 12: 3886-3897

Google Scholar: Author Only Title Only Author and Title

Falhof J, Pedersen JT, Fuglsang AT, Palmgren M (2016) Plasma Membrane H+-ATPase Regulation in the Center of Plant Physiology. Molecular Plant 9: 323-337

Google Scholar: Author Only Title Only Author and Title

Fuglsang AT, Kristensen A Cuin TA, Schulze WX, Persson J, Thuesen KH, Ytting CK, Oehlenschlaeger CB, Mahmood K, Sondergaard TE, Shabala S, Palmgren MG (2014) Receptor kinase-mediated control of primary active proton pumping at the plasma membrane. Plant Journal 80: 951-964

Google Scholar: Author Only Title Only Author and Title

Grubb LE, Derbyshire P, Dunning KE, Zpfel C, Menke FLH, Monaghan J (2021) Large-scale identification of ubiquitination sites on membrane-associated proteins in Arabidopsis thaliana seedlings. Plant Physiology 185: 1483-1488

Google Scholar: Author Only Title Only Author and Title 
Guo JH, Liu JX, Wei Q, Wang RM, Yang WY, Ma YY, Chen GJ, Yu YX (2017) Proteomes and Ubiquitylomes Analysis Reveals the Involvement of Ubiquitination in Protein Degradation in Petunias. Plant Physiology 173: 668-687

Google Scholar: Author Only Title Only Author and Title

Guo QF, Zhang J, Gao Q, Xing SC, Li F, Wang W(2008) Drought tolerance through overexpression of monoubiquitin in transgenic tobacco. Journal of Plant Physiology 165: 1745-1755

Google Scholar: Author Only Title Only Author and Title

Haglund K, Shimokawa N, Szymkiewicz I, Dikic I (2002) Cbl-directed monoubiquitination of CIN85 is involved in regulation of ligandinduced degradation of EGF receptors. Proceedings of the National Academy of Sciences of the United States of America 99: 1219112196

Google Scholar: Author Only Title Only Author and Title

He DL, Li M, Damaris RN, Bu C, Xue JY, Yang PF (2020) Quantitative ubiquitylomics approach for characterizing the dynamic change and extensive modulation of ubiquitylation in rice seed germination. Plant Journal 101: 1430-1447

Google Scholar: Author Only Title Only Author and Title

Johanson U, Gustavsson S (2002) Anew subfamily of major intrinsic proteins in plants. Molecular Biology and Evolution 19: $456-461$ Google Scholar: Author Only Title Only Author and Title

Johnson A Vert G (2016) Unraveling K63 Polyubiquitination Networks by Sensor-Based Proteomics. Plant Physiology 171: $1808-1820$ Google Scholar: Author Only Title Only Author and Title

Jones AM, Xuan YH, Xu M, Wang RS, Ho CH, Lalonde S, You CH, Sardi MI, Parsa SA, Smith-Valle E, Su TY, Frazer KA, Pilot G, Pratelli R, Grossmann G, Acharya BR, Hu HC, Engineer C, Villiers F, Ju CL, Takeda K, Su Z, Dong QF, Assmann SM, Chen J, Kwak JM, Schroeder JI, Albert R, Rhee SY, Frommer WB (2014) Border control - Amembrane-linked interactome of Arabidopsis. Science 344: 711-716

Google Scholar: Author Only Title Only Author and Title

Kang HH, Zhang M, Zhou SM, Guo QF, Chen FJ, Wu JJ, Wang W(2016) Overexpression of wheat ubiquitin gene, Ta-Ub2, improves abiotic stress tolerance of Brachypodium distachyon. Plant Science 248: 102-115

Google Scholar: Author Only Title Only Author and Title

Kim DY, Scalf M, Smith LM, Vierstra RD (2013) Advanced proteomic analyses yield a deep catalog of ubiquitylation targets in Arabidopsis. Plant Cell 25: 1523-1540

Google Scholar: Author Only Title Only Author and Title

Komander D, Rape M (2012) The Ubiquitin Code. In RD Kornberg, ed, Annual Review of Biochemistry, Vol 81, Vol 81. Annual Reviews, Palo Alto, pp 203-229

Google Scholar: Author Only Title Only Author and Title

Laemmli UK (1970) Cleavage of structural proteins during the assembly of the head of bacteriophage T4. Nature 222: 680-865

Google Scholar: Author Only Title Only Author and Title

Lee HJ, Li CF, Ruan DN, Powers S, Thompson PA, Frohman MA Chan CH (2016) The DNADamage Transducer RNF8 Facilitates Cancer Chemoresistance and Progression through Twist Activation. Molecular Cell 63: 1021-1033

Google Scholar: Author Only Title Only Author and Title

Liu TY, Huang TK, Tseng CY, Lai YS, Lin SI, Lin WY, Chen JW, Chiou TJ (2012) PHO2-Dependent Degradation of PHO1 Modulates Phosphate Homeostasis in Arabidopsis. Plant Cell 24: 2168-2183

Google Scholar: Author Only Title Only Author and Title

Lobell DB, Schlenker W, Costa-Roberts J (2011) Climate Trends and Global Crop Production Since 1980. Science 333: 616-620 Google Scholar: Author Only Title Only Author and Title

Manzano C, Abraham Z, Lopez-Torrejon G, Del Pozo JC (2008) Identification of ubiquitinated proteins in Arabidopsis. Plant Molecular Biology 68: 145-158

Google Scholar: Author Only Title Only Author and Title

Maor R, Jones A, Nuhse TS, Studholme DJ, Peck SC, Shirasu K (2007) Multidimensional protein identification technology (MudPIT) analysis of ubiquitinated proteins in plants. Molecular \& Cellular Proteomics 6: 601-610

Google Scholar: Author Only Title Only Author and Title

Martiniere A, Fiche JB, Smokvarska M, Mari S, Acon C, Dumont X, Hematy K, Jaillais Y, Nollmann M, Maurel C (2019) Osmotic Stress Activates Two Reactive Oxygen Species Pathways with Distinct Effects on Protein Nanodomains and Diffusion. Plant Physiology 179: 1581-1593

Google Scholar: Author Only Title Only Author and Title

Marx C, Held JM, Gibson BW, Benz CC (2010) ErbB2 Trafficking and Degradation Associated with K48 and K63 Polyubiquitination. Cancer Research 70: 3709-3717

Google Scholar: Author Only Title Only Author and Title

Maurel C, Boursiac Y, Luu D-T, Santoni V, Shahzad Z, Verdoucq L (2015) Aquaporins in Plants. Physiological reviews 95: $1321-1358$

Google Scholar: Author Only Title Only Author and Title 
Mi HY, Muruganujan A Casagrande JT, Thomas PD (2013) Large-scale gene function analysis with the PANTHER classification system Nature Protocols 8: 1551-1566

Google Scholar: Author Only Title Only Author and Title

Mukhopadhyay D, Riezman H (2007) Proteasome-independent functions of ubiquitin in endocytosis and signaling. Science 315: 201-205 Google Scholar: Author Only Title Only Author and Title

Nelson CJ, Millar AH (2015) Protein turnover in plant biology. Nature Plants 1

Google Scholar: Author Only Title Only Author and Title

O'Shea JP, Chou MF, Quader SA, Ryan JK, Church GM, Schwartz D (2013) pLogo: a probabilistic approach to visualizing sequence motifs. Nature methods 10: 1211-+

Google Scholar: Author Only Title Only Author and Title

Pan WB, Lin BY, Yang XY, Liu LJ, Xia R, Li JG, Wu YR, Xie Q (2020) The UBC27-ARP3 ubiquitination complex modulates ABA signaling by promoting the degradation of ABI1 in Arabidopsis. Proceedings of the National Academy of Sciences of the United States of America 117: 27694-27702

Google Scholar: Author Only Title Only Author and Title

Pickart CM, Eddins MJ (2004) Ubiquitin: structures, functions, mechanisms. Biochim. Biophys. Acta-Molecular Cell Research 1695: 5572

Google Scholar: Author Only Title Only Author and Title

Quigley F, Rosenberg JM, Shachar-Hill Y, Bohnert HJ (2002) From genome to function: the Arabidopsis aquaporins. Genome Biology 3: 1-17

Google Scholar: Author Only Title Only Author and Title

Romero-Barrios N, Monachello D, Dolde U, Wong A, San Clemente H, Cayrel A, Johnson A, Lurin C, Vert G (2020) Advanced Cataloging of Lysine-63 Polyubiquitin Networks by Genomic, Interactome, and Sensor-Based Proteomic Analyses. Plant Cell 32: 123-138 Google Scholar: Author Only Title Only Author and Title

Romero-Barrios N, Vert G (2018) Proteasome-independent functions of lysine-63 polyubiquitination in plants. New Phytologist 217: 9951011

Google Scholar: Author Only Title Only Author and Title

Santoni V, Verdoucq L, Sommerer N, Vinh J, Pflieger D, Maurel C (2006) Methylation of aquaporins in plant plasma membrane. Biochem J. 400: 189-197

Google Scholar: Author Only Title Only $\underline{\text { Author and Title }}$

Shannon P, Markiel A, Ozier O, Baliga NS, Wang JT, Ramage D, Amin N, Schwikowski B, Ideker T (2003) Cytoscape: Asoftware environment for integrated models of biomolecular interaction networks. Genome Res. 13: 2498-2504

Google Scholar: Author Only Title Only Author and Title

Sharma B, Bhatt TK (2018) Genome-wide identification and expression analysis of E2 ubiquitin-conjugating enzymes in tomato (vol 7, 8613, 2017). Scientific Reports 8

Google Scholar: Author Only Title Only Author and Title

Stone SL (2018) Role of the Ubiquitin Proteasome System in Plant Response to Abiotic Stress. In L Galluzzi, ed, International Review of Cell and Molecular Biology, Vol 343, Vol 343. Academic Press Ltd-Elsevier Science Ltd, London, pp 65-110

Google Scholar: Author Only Title Only Author and Title

Svozil J, Hirsch-Hoffmann M, Dudler R, Gruissem W, Baerenfaller K (2014) Protein Abundance Changes and Ubiquitylation Targets Identified after Inhibition of the Proteasome with Syringolin A Molecular \& Cellular Proteomics 13: $1523-1536$

Google Scholar: Author Only Title Only Author and Title

Tsuchiya H, Tanaka K, Saeki Y (2013) The parallel reaction monitoring method contributes to a highly sensitive polyubiquitin chain quantification. Biochem Biophys Res Commun 436: 223-229

Google Scholar: Author Only Title Only Author and Title

Turek I, Tischer N, Lassig R, Trujillo M (2018) Multi-tiered pairing selectivity between E2 ubiquitin-conjugating enzymes and E3 ligases. Journal of Biological Chemistry 293: 16324-16336

Google Scholar: Author Only Title Only Author and Title

Valencia JP, Goodman K, Otegui MS (2016) Endocytosis and Endosomal Trafficking in Plants. In SS Merchant, ed, Annual Review of Plant Biology, Vol 67, Vol 67. Annual Reviews, Palo Ato, pp 309-335

Google Scholar: Author Only Title Only Author and Title

Vu LD, Gevaert K, De Smet I (2018) Protein Language: Post-Translational Modifications Talking to Each Other. Trends in Plant Science 23: 1068-1080

Google Scholar: Author Only Title Only Author and Title

Walsh CK, Sadanandom A(2014) Ubiquitin chain topology in plant cell signaling: a new facet to an evergreen story. Front. Plant Sci. 5: 122 
Google Scholar: Author Only Title Only Author and Title

Walton A, Stes E, Cybulski N, Van Bel M, Inigo S, Durand AN, Timmerman E, Heyman J, Pauwels L, De Veylder L, Goossens A, De Smet I, Coppens F, Goormachtig S, Gevaert K (2016) It's Time for Some "Site"-Seeing: Novel Tools to Monitor the Ubiquitin Landscape in Arabidopsis thaliana. Plant Cell 28: 6-16

Google Scholar: Author Only Title Only Author and Title

Wang YF, Chao Q, Li Z, Lu T-C, Zheng H-Y, Zhao C-F, Shen Z, Li X-H, Wang B-C (2019) Large-scale Identification and Time-course Quantification of Ubiquitylation Events During Maize Seedling De-etiolation. Genomics Proteomics Bioinformatics 17: 603-622

Google Scholar: Author Only Title Only Author and Title

Xie X, Kang HX, Liu WD, Wang GL (2015) Comprehensive Profiling of the Rice Ubiquitome Reveals the Significance of Lysine Ubiquitination in Young Leaves. Journal of Proteome Research 14: 2017-2025

Google Scholar: Author Only Title Only Author and Title

Xu P, Hankins HM, MacDonald C, Erlinger SJ, Frazier MN, Diab NS, Piper RC, Jackson LP, MacGurn JA, Graham TR (2017) COPI mediates recycling of an exocytic SNARE by recognition of a ubiquitin sorting signal. Elife 6

Google Scholar: Author Only Title Only Author and Title

Zhang L, Yu ZP, Xu Y, Yu M, Ren Y, Zhang SZ, Yang GD, Huang JG, Yan K, Zheng CC, Wu CG (2021) Regulation of the stability and ABA import activity of NRT1.2/NPF4.6 by CEPR2-mediated phosphorylation in Arabidopsis. Molecular Plant 14: 633-646

Google Scholar: Author Only Title Only Author and Title

Zhang N, Xu J, Liu XY, Liang WX, Xin MM, Du JK, Hu ZR, Peng HR, Guo WL, Ni ZF, Sun QX, Yao YY (2019) Identification of HSP90C as a substrate of E3 ligase TaSAP5 through ubiquitylome profiling. Plant Science 287

Google Scholar: Author Only Title Only Author and Title

Zhang N, Zhang LR, Shi CN, Tian QZ, Lv GG, Wang Y, Cui DQ, Chen F (2017) Comprehensive profiling of lysine ubiquitome reveals diverse functions of lysine ubiquitination in common wheat. Scientific Reports 7

Google Scholar: Author Only Title Only Author and Title

Zheng L, Chen YJ, Ding D, Zhou Y, Ding LP, Wei JH, Wang HZ(2019) Endoplasmic reticulum-localized UBC34 interaction with lignin repressors MYB221 and MYB156 regulates the transactivity of the transcription factors in Populus tomentosa. BMC Plant Biology 19

Google Scholar: Author Only Title Only Author and Title

Zhiguo E, Zhang YP, Li TT, Wang L, Zhao HM (2015) Characterization of the Ubiquitin-Conjugating Enzyme Gene Family in Rice and Evaluation of Expression Profiles under Abiotic Stresses and Hormone Treatments. Plos One 10

Google Scholar: Author Only Title Only Author and Title

Zhou GA, Chang RZ, Qiu LJ (2010) Overexpression of soybean ubiquitin-conjugating enzyme gene GmUBC2 confers enhanced drought and salt tolerance through modulating abiotic stress-responsive gene expression in Arabidopsis. Plant Molecular Biology 72 : 357-367

Google Scholar: Author Only Title Only Author and Title 